Let each apportion a part of the calculation, and then print it in an agreed form. The sterotype plates would be interchanged, and what a private firm does the Government can effect. In this way the English-spealing marine, including many Dutch and German captains, will be at once supplied, and part of the proposed economy and benefit be obtained without waiting for negotiations with France and Germany. HyDE CLARKE

\section{Electrical Phenomenon in Mid-Lothian}

I HAVE observed in a daily contemporary a communication quoted from your journal $w$ ith reference to this occurrence on the 23rd ult.

For the information of those of your readers who are interested in such matters perhaps you will kindly allow me to observe that I also witnessed a similar, or the same, phenomenon that evening.

When driving home from a professional visit in the country, and a mile south of this town, about ten o'clock I was suddenly startled by a peculiar sensation or slight shock, and immediately perceived, ten yards in front, on the road, a bright opalescent luminosity which travelled deliberately away in a northerly direction. This cloud or wave of light covered the whole breadth of the road, and was distinctly visible for some seconds. It seemed to rest entirely on the ground, and in character reminded one somewhat of the illumination resulting from the electric light. I should imagine it was travelling at the rate of twenty miles an hour, as it was going much in the same direction I was, but of course much faster. The part of the road where it showed itself is lined by high trees on both sides in full foliage. I heard no thunder and saw no lightning or meteor to account for the strange and weird-looking light.

The interesting question then arises, What was the nature of this phenomenon?

It will be remembered that the thermometer was for several days at that time above $80^{\circ} \mathrm{F}$. in the shade. Might it not be possible, therefore, for a certain volume of air to become electrified, and then, perfectly insulated by the dry surrounding atmosphere, show its existence in this manner as a luminous cloud rushing along the ground?

I may mention in conclusion that my groom, who was driving me at the time, also witnessed the occurrence.

Dalkeith, N.B., August Io, I 885

Robert Lucas

\section{On a Radiant Energy Recorder}

A FEW weeks ago I wrote a short article for NATURE under the above title, describing an instrument for the measurement of radiation in heat units which was based upon the principle of the integration of temperature by the distillation of water in vacuo. Since then Mr. Edward Vivian, M.A., has kindly written me a very interesting letter, in which he says that he had several forms of an instrument based upon essentially the same principles, made for him by Messrs. Negretti and Zambra many years ago, and that some of them are still in use in his garden at Torquay. Mr. Vivian's instruments were slown at the British Association (B. A. Report, 1856, p. 48) and at the Royal Institution of Great Britain (Fournal R. T., I857, p. 438), but no description of them appears to have been printed, which probably accounts for their not being nore generally known.

University College, Liverpool

J. W. ClaRK

\section{Our Ancestors}

THE number of "Our Ancestors" since "the time of the Norman Conquest," mentioned in your last issue by $\left(\begin{array}{c}\mathbf{I} \\ 2\end{array}\right)^{n}$, and the consequences to be deduced therefrom, have been very interestingly discussed already by $\mathrm{Mr}$. Grove in his presidential address to the British Association at Nottingham, r866.

Freiburg, Badenia, Angust 8

N.

\section{THE INSTITUTION OF MECHANICAL ENGINEERS}

$\mathrm{HE}$ Institution of Mechanical Engineers held their summer meeting at Lincoln last week, under the presidency of Mr. Jeremiah Head, who, in his inaugural address, treated of the relative advantages of iron and steel for the various purposes for which these metals are employed. The reasons why steel rails are now used almost to the exclusion of iron are that they can be produced more cheaply, can be manufactured of equally good quality by either the Bessemer or Siemens process with either acid or basic-lined vessels and of almost any iron ore, and they can better withstand abrasion, disintegration, or crushing under heavy rolling loads; for the same reasons steel tires are now almost universally employed. For ship-building steel is superior to iron, as, owing to its greater ductility, ships built of the former metal are able to outlive collisions and minor accidents that would be fatal to iron ships. As is well known, owing to the superior tensile strength of steel, Lloyd's Committee agreed in 1877 to allow a reduction of 20 per cent. in weight of scantlings over iron, and in the thickness of plates; Mr. Head argues that, considering a ship's plate is a broad girder, its strength diminishes as the square of the thickness, and that, therefore, although a steel ship would be superior to an iron one of equal weight, an iron ship is likely to retain its form better than a steel one built 20 per cent. lighter. As regards bridges and roofs, the employment of iron or steel depends mainly upon the size of the structure; for light edifices, owing to its greater cheapness, iron has hitherto been used, whilst for large spans, where the weight of the structure itself is an important function, steel has been employed in the erection of bridges of spans which could not have been attempted if the engineer had been dependent on iron alone. For boilers, except in the matter of corrosion, in which authorities seem to differ as to the resisting power of iron and steel, but appear to be rather favourable to the former, steel is much. more advantageous than iron, both on account of its being as cheap, and on account of a steam boiler of the same weight being able to withstand much higher pressures if made of steel than if made of iron; hence boilers, and marine boilers particularly, are now scarcely ever built of iron. The President recommended the application of metal in the construction of the frames of rolling stock and for railway-sleepers. As regards the continued use of wooden sleepers, there can be no question that "it is a form of waste that should be reprehended in the public interest, just as should the use of coal for ballasting or other obviously wasteful purpose. The same timber which would become useless for sleepers in, say, nine years, would last at least a century in the roof or flooring of a house." Another argument advanced, and a most important one, is that the substitution of iron and steel for timber railway-sleepers would not only give an enormous impetus to these industries while the substitution was being effected, but would permanently maintain a population of 100,000 , or 3 per cent. of the whole population of the country, for renewals.

Leaving special branches of industry, to refer to special forms in which iron and steel are supplied, the President drew attention to bar-iron still maintaining its position, because wherever implements are made they come sooner or later to the village blacksmith to be repaired, and these find steel harder to work, more difficult to weld, and requiring more care to smith; and therefore the original manufacturer has to adopt a material and construction within the compass of the ideas and resources of the rural repairer.

As regards castings, an urgent need has long existed for a material which could be cast in a mould, and which should yet have the toughness and tenacity of wrought iron; and steel, exactly supplying this want, has come very generally into use, more particularly as the cost of steel castings has been greatly cheapened latterly by the employment of the Bessemer and Open Hearth processes ; still, steel castings are much dearer than iron ones, because the molten metal is dearer, and the higher melting point of steel compared with iron necessitates more costly moulds. But in a majority of cases in which cast 